\title{
Orchard Factors Associated with Resistance and Cross Resistance to Sterol Demethylation Inhibitor Fungicides in Populations of Venturia inaequalis from Pennsylvania
}

\author{
Emily E. Pfeufer and Henry K. Ngugi
}

Department of Plant Pathology, Pennsylvania State University, Fruit Research \& Extension Center, Biglerville 17307.

Accepted for publication 3 October 2011.

\begin{abstract}
Pfeufer, E. E., and Ngugi, H. K. 2012. Orchard factors associated with resistance and cross resistance to sterol demethylation inhibitor fungicides in populations of Venturia inaequalis from Pennsylvania. Phytopathology 102:272-282.

Orchard management practices, such as destroying of overwintered inoculum and limiting the number of fungicide applications, are often recommended as tactics for slowing the development of resistance to sterol demethylation-inhibitor (DMI) fungicides in populations of Venturia inaequalis. However, there is little quantitative evidence relating the use of such practices to levels of resistance in orchards. The aim of this study was to evaluate the sensitivity of $V$. inaequalis isolates from Pennsylvania to DMI fungicides, and to identify orchard management factors related to the incidence of resistant isolates. In total, 644 single-spore $V$. inaequalis cultures obtained from 20 apple orchards in 2008 or 2009 were tested for sensitivity to myclobutanil, fenbuconazole, or difenoconazole. Growers provided management history of the sampled plots. Widespread shifts

$0.187 \mu \mathrm{g} / \mathrm{ml}$ for myclobutanil, fenbuconazole, and difenoconazole, respectively. Cross resistance to the three fungicides was documented in high correlation (Spearman's $r>0.6$ ) between mean $\mathrm{EC}_{50}$ values for 14 orchards. Based on a $0.5-\mu \mathrm{g} / \mathrm{ml}$ threshold, 66 and $26 \%$ of isolates were resistant to myclobutanil and fenbuconazole, respectively, and $22 \%$ were cross resistant to the two fungicides. A significant between-year shift toward increased resistance was noted in two of three orchards surveyed in both years. Failure to use dormant copper sprays, older trees, larger orchards, orchards with $\leq 10$ cultivars, and application of $>4$ DMI sprays were positively correlated $(0.0001<P<0.05)$ with the incidence of resistant isolates. Isolates from orchards with $>4$ DMI sprays were four times as likely to be resistant to fenbuconazole (odds ratio $=4.57 ; P=$ 0.015). Isolates from orchards without dormant copper sprays were twice as likely to be cross-shifted toward resistance to all three fungicides (odds ratio $=1.76 ; P=0.048$ ). Results identify management practices that can reduce the risk of $V$. inaequalis developing resistance to DMI fungicides.
\end{abstract} toward resistance to the three fungicides were noted, with mean effective concentration for $50 \%$ inhibition $\left(\mathrm{EC}_{50}\right)$ values of $2.136,0.786$, and

Apple scab, caused by Venturia inaequalis (Cooke) G. Winter, is one of the most economically damaging diseases of apple, the most important fruit crop in the northeastern United States. Although apple scab has been recognized for $>400$ years, control is difficult and scab epidemics remain a problem for many of today's growers $(5,23,24)$. Management of apple scab consists of two main strategies: use of cultural control methods and application of chemical fungicides. Chemical fungicides are the most effective and economical tools for scab management in commercial apple production (23). However, the reliance on chemical fungicides has its challenges, including human and environmental health concerns, as well as the development of resistance to the active ingredients in populations of $V$. inaequalis, all of which can result in deregistration.

Among the chemical fungicides, the sterol demethylationinhibitor (DMI) fungicides serve as the backbone of apple disease management programs in the northeastern United States, where the focus is primarily on scab control. DMI fungicides are characterized by a single-site mode of action, and are classified as having a medium risk for resistance development according to

Corresponding author: H. K. Ngugi; E-mail address: hkn3@psu.edu

*The $\boldsymbol{e}$-Xtra logo stands for "electronic extra" and indicates that Figure 3 appears in color online.

http://dx.doi.org/10.1094/PHYTO-04-11-0117

(C) 2012 The American Phytopathological Society
Additional keywords: generalized linear mixed models. their Fungicide Resistance Action Committee code. Resistance to DMI fungicides in populations of $V$. inaequalis from commercial apple orchards was first reported in 1997 in populations from New York (20). Since then, V. inaequalis resistance to these fungicides has been documented in most major apple-growing areas in North America $(10,14,17,20,25,31)$ but a thorough study in Pennsylvania, the fourth-leading state in apple production in the United States, has never been undertaken.

$V$. inaequalis resistance to DMI fungicides is suggested to develop quantitatively over a number of years (31). DMI fungicides achieve control through a single-site mode of action by inhibiting 14- $\alpha$-demethylase, which is critical to the biosynthesis of ergosterol (30). Despite this single-site activity, several mechanisms have been suggested to confer resistance in fungal pathogens; these include the overexpression of CYP51 (31), point mutations in CYP51 $(8,9,37)$, and the presence of cellular efflux mechanisms (7). The possibility of multiple mechanisms conferring resistance suggests that, even under similar environmental conditions, the status of resistance to DMI fungicides is likely to differ among populations from different orchards as a result of differential impacts of management practices on the various mechanisms. Moreover, because $V$. inaequalis has a localized sporedispersal pattern (2), we hypothesize that migration events play a limited role in the development of fungicide resistance. Thus, orchard-specific management practices may be the key factors determining the level of resistance to DMI fungicides.

Within the apple industry, orchard management practices differ tremendously among enterprises depending on many factors, in- 
cluding economics, orchard history, geographical location, practical convenience, and a multitude of other conditions. Some of these orchard-specific factors, such as the type and number of cultivars, age and size of the trees, planting pattern of the orchards (e.g., blocks of single cultivars versus alternating rows of multiple cultivars), and fungicide spray programs and methods (e.g., alternate-row middle [ARM] as opposed to complete sprays, or limiting the number of DMI fungicide applications per season), as well as the targeted market for the crop (i.e., fresh or processing market), are thought to influence the rate at which the populations of the scab fungus shift toward resistance to the DMI fungicides; however, there is a paucity of data to support this hypothesis.

Cultural practices used for apple scab management entail preventative tactics designed to either reduce primary inoculum or create an unfavorable environment for $V$. inaequalis development, spore production, and spread $(6,24)$. Such practices may include altering tree spacing and performing regular pruning to maintain air circulation in the canopy $(6,12,16,24)$; shredding leaves or stimulating microbial breakdown of debris $(12,33)$; and planting a mixture of cultivars, including those with resistance (3). In addition to their role as scab control methods, these practices, along with the use of copper or urea during dormant stages of tree growth, are also routinely recommended as tactics for slowing the development of resistance to fungicides in populations of $V$. inaequalis $(29,34)$. However, whereas the effectiveness of these practices in the integrated control of apple scab has been confirmed in many studies $(12,24,33)$, their impact on the development of resistance to DMI fungicides in populations of $V$. inaequalis has never been investigated. Evidence relating these cultural and orchard management practices to the levels of resistance to DMI fungicides in commercial apple orchards is needed in order to support their recommendation as tools for mitigating the risk of resistance development.

The overall goal of this study was to develop recommendations to manage the risk of resistance to DMI fungicides in populations of $V$. inaequalis. We hypothesized that the levels of resistance to DMI fungicides would be variable among orchards in Pennsylvania but strongly related to orchard-specific management practices. The specific objectives were to (i) document the incidence of resistance to the DMI fungicides myclobutanil, fenbuconazole, and difenoconazole in populations of $V$. inaequalis from Pennsylvania apple orchards and investigate the incidence of cross resistance to these fungicides; and (ii) identify orchard-specific cultural and management factors related to the incidence of resistance to the DMI fungicides.

\section{MATERIALS AND METHODS}

Orchard survey and sample collection. In all, six orchards were surveyed in June to July 2008 and 14 orchards were sampled from late May to mid-July 2009. Most of the orchards surveyed were in or around Adams County, in a region that accounts for $\approx 70 \%$ of the total acreage under apple in Pennsylvania. Leaves and immature fruit with scab symptoms were collected from the cultivars 'Fuji,' 'Golden Delicious,' 'Delicious,' 'Rome Beauty,' and 'York Imperial.' In 2008, samples were taken from suspected problem areas of the blocks from at least four trees whereas, in 2009, samples were obtained from five trees of each cultivar sampled in a 'W' pattern across blocks of 0.81 to 2.02 ha in size. Samples were kept in brown paper bags in a cold room at $4{ }^{\circ} \mathrm{C}$ until further processing. During the isolation process, efforts were made to ensure that the isolate cohorts equally represented each of the sampling points from a block and cultivar; a master list was prepared to keep track of the origin of each isolate. V. inaequalis cultures of two isolates with baseline sensitivity and two isolates confirmed as resistant to DMI fungicides from Dr. Kerik Cox (Department of Plant Pathology, Cornell University) were used as positive and negative controls, respectively, with each batch of media made. A nonexposed, baseline population was not locally available.

Grower survey on management strategies. Growers completed a written questionnaire on orchard-specific characteristics and apple scab management tactics used in the sampled blocks. Data was obtained on the overall size of the orchard, the number of cultivars grown, the age of the sampled trees, the cultivar and rootstock of the sampled trees, and the planting pattern (or arrangement) of the trees within the sampled plot (i.e., whether trees were grown in a monoculture block or in row-by-row mixtures). Growers were also surveyed on the history of DMI fungicide use in the sampled plots, whether applications were made as full sprays or ARM sprays, whether the grower used copper on dormant trees, and whether the leaf litter was managed in any way in the fall and winter months (e.g., subjected to leaf shredding with a mower or other equipment).

V. inaequalis isolation. All isolations were carried out on quarter-strength potato dextrose agar (1/4 PDA) prepared by suspending $5 \mathrm{~g}$ of PDA and $5 \mathrm{~g}$ of agar in $500 \mathrm{ml}$ of deionized water and autoclaving for $15 \mathrm{~min}$ at $120^{\circ} \mathrm{C}$. Using a scalpel, a single sporulating lesion was excised from a leaf or fruit and streaked, spore-side down, onto 100 -mm-diameter petri plates of 1/4 PDA medium amended with either streptomycin at 100 parts per million $(\mathrm{ppm})$ or tetracycline at $50 \mathrm{ppm}$. Plates were incubated at $25^{\circ} \mathrm{C}$ with $\approx 12 \mathrm{~h}$ of light in the laboratory. Then, 24 to $48 \mathrm{~h}$ later, the plates were viewed under a Nikon or Olympus dissecting microscope at $100 \times$ magnification. A germinating conidium was chosen and aseptically transferred to a fresh plate containing 1/4 PDA to obtain a single-spore culture. This procedure was repeated for 74 samples from three orchards in 2008 and 579 samples from 2009.

Screening for resistance to DMI fungicides. Isolates were screened for resistance to myclobutanil, fenbuconazole, and difenoconazole using the agar plug assay described by Smith et al. (32) and Köller et al. (20), with minor modifications as described below. Technical-grade myclobutanil, fenbuconazole, and difenoconazole were obtained from the manufacturers (Dow Agrochemicals [mycobutanil and fenbuconazole], and Syngenta [difenoconazole]). Fungicides were suspended in $70 \%$ ethanol and filter-sterilized with a $0.2-\mu \mathrm{m}$ polyethersulfone filter (VWR International). Media (1/4 PDA) were amended with myclobutanil at $0,0.05,0.125,0.5,1.0$, or $2.5 \mu \mathrm{g} / \mathrm{ml}$ or with fenbuconazole or difenoconazole at $0,0.05,0.125,0.25,0.5$, or $1.25 \mu \mathrm{g} / \mathrm{ml}$. Fungicide was added to media maintained at $55^{\circ} \mathrm{C}$, which was then stirred for $60 \mathrm{~s}$ to ensure uniform distribution before dispensing into 60-mm-diameter plates.

Cultures were transferred onto fungicide-amended plates after $\approx 2$ months of growth on nonamended 1/4 PDA, when colonies were $\approx 3 \mathrm{~cm}$ in diameter. Plug transfer was accomplished by using a $0.32-\mathrm{cm}$-diameter cork borer to remove medium out of the center of the fungicide-amended plates, to create core holes for holding the mycelial plugs. A $0.32-\mathrm{cm}$-diameter mycelial plug was then removed from the advancing edge of an isolate culture and placed in the core hole. Three replicate plates of each fungicide concentration were prepared for each isolate tested. In total, 644, 545, and 539 isolates were individually assayed on at least three concentrations of myclobutanil, fenbuconazole, and difenoconazole, respectively. Of these, 563 isolates on myclobutanil, 395 on fenbuconazole, and 385 on difenoconazole were assayed in five or more concentrations to estimate the mean effective concentration necessary to cause $50 \%$ inhibition $\left(\mathrm{EC}_{50}\right)$ values. By the time the study was completed, 498 of the 644 total isolates obtained had separately been tested on all three fungicides, with the remaining isolates being assayed on one or more of the fungicides. In all assays, $>70 \%$ of the isolates obtained from each orchard were evaluated.

After plating, isolates were incubated in the dark at $23^{\circ} \mathrm{C}$ in either an incubator or plastic containers kept in drawer cabinets in 
a laboratory, with closely monitored room temperature set at $25^{\circ} \mathrm{C}$. Ten days were allowed to pass before commencing weekly measurements of colony diameter. Each fungal colony was measured across the same two perpendicular diameters each week, for a total of five measurements. An average diameter was calculated from the two measurements for each replicate of each fungicide concentration after the fifth week of measurement.

Statistical analysis. Estimates of orchard mean $E C_{50}$ values. For each isolate plated on a given fungicide, the relative growth (RG) value was calculated by dividing the average diameter of the colony on the respective fungicide concentration after 45 days of growth by the average diameter of the colony of the same isolate and age grown on nonamended 1/4 PDA plate and multiplying by
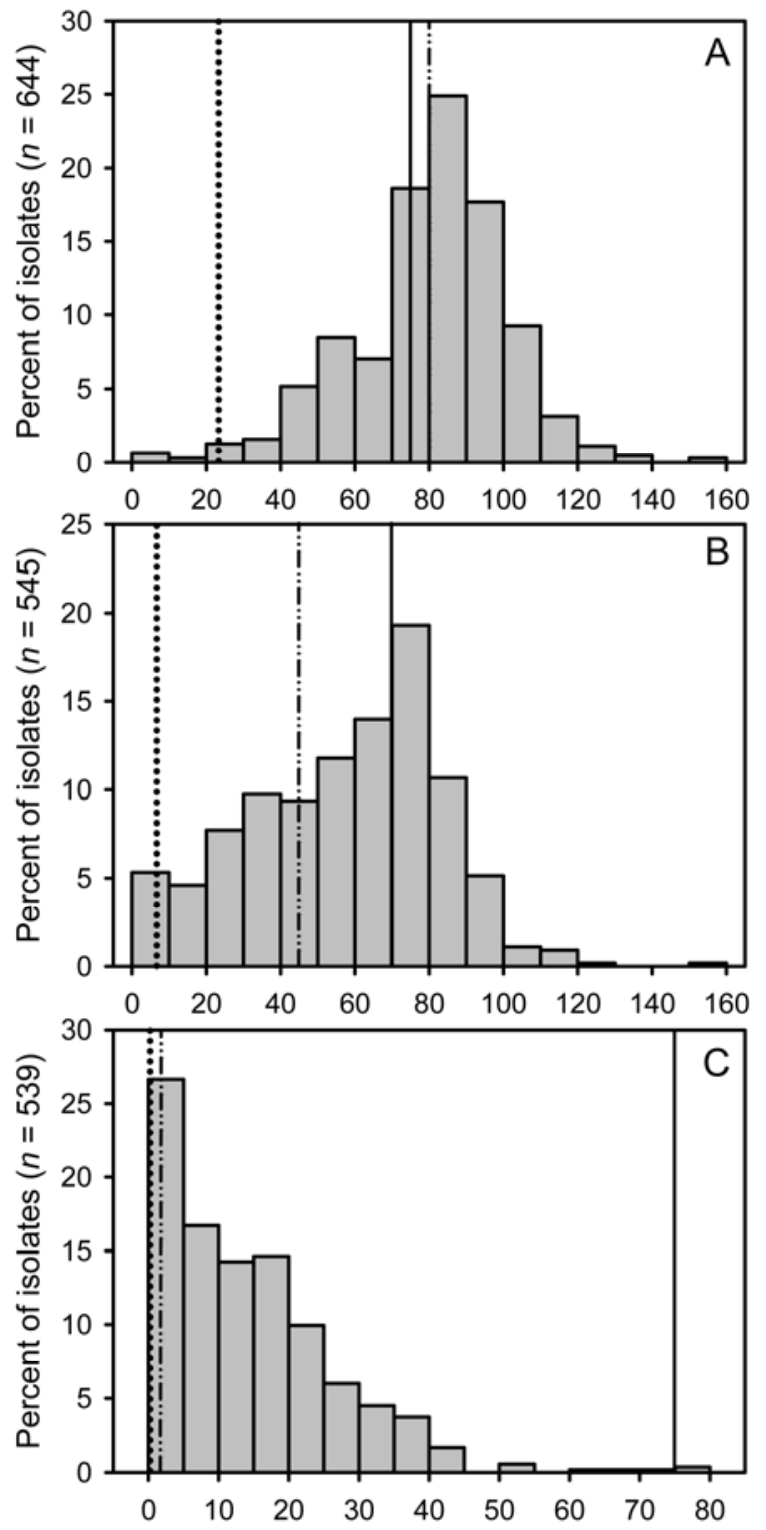

Relative growth on $0.5 \mu \mathrm{g} / \mathrm{ml}$ of fungicide

Fig. 1. Distributions of relative growth (RG) values of Venturia inaequalis isolates from Pennsylvania apple orchards on $\mathbf{A}$, myclobutanil; $\mathbf{B}$, fenbuconazole; or $\mathbf{C}$, difenoconazole at $0.5 \mu \mathrm{g} / \mathrm{ml}$, based on samples collected in 2008 and 2009. Bars represent percent isolates grouped according to RG values based on sample sizes of 644, 545, and 539 for myclobutanil, fenbuconazole, and difenoconazole, respectively. Dotted vertical lines indicate the average RG value of two confirmed baseline isolates (A, $n=31$; B, $n=27$; and C, $n=25$ ) and dot-dash vertical lines indicate the average $\mathrm{RG}$ value of two isolates with confirmed shifted sensitivity (A, $n=33 ; \mathrm{B}, n=27$; and $\mathrm{C}, n=25$ ). Solid vertical lines indicate a threshold value $(R G=75)$; isolates with $R G$ above this threshold were determined to be resistant to the respective fungicide.
100 (20). The mean $\mathrm{EC}_{50}$ was then computed for each withinorchard population with the PROBIT procedure of SAS (SAS version 9.2; SAS Institute Inc.). RG values were regressed against the log of each concentration of the fungicide and the $\mathrm{EC}_{50}$ value and its corresponding $95 \%$ confidence limits were determined from the regression, as described by Hsiang et al. (13). The effects of cultivar on $\mathrm{EC}_{50}$ values were also evaluated as a term in the probit regression model, and orchards where cultivars had significantly different $(P<0.05) \mathrm{EC}_{50}$ values were noted. Mean $E_{50}$ values were computed only for 14 of the 20 orchards surveyed.

Tests for shifts toward increased resistance. To test for shifts toward resistance to the DMI fungicides, $\mathrm{EC}_{50}$ values and distributions of $\mathrm{RG}$ values on myclobutanil at $0.5 \mu \mathrm{g} / \mathrm{ml}$ for isolates from three orchards sampled in both 2008 and 2009 were compared using a two-sample $t$ test and the Kolmogorov-Smirnov $(\mathrm{K}-\mathrm{S})$ statistic, respectively. The mean $\mathrm{EC}_{50}$ values were analyzed with and without a natural logarithm transformation.

Modeling orchard management factors associated with resistance to DMI fungicides. To assess the effects of orchard management and cultural practices on sensitivity of $V$. inaequalis populations to DMI fungicides, growth responses of individual isolates on plates amended with the active ingredient at $0.5 \mu \mathrm{g} / \mathrm{ml}$ were evaluated for each of the three fungicides. Two response variables were analyzed for each fungicide: (i) the $R G$ value for each isolate at the $0.5 \mu \mathrm{g} / \mathrm{ml}$ threshold and (ii) a binary variable in which isolates with $R G$ values $\geq 75$ were classified as resistant and assigned a value of 1 while those with $R G$ values $<75$ were designated as sensitive and assigned a 0 . For a given population, an RG value determined at a specific concentration of a DMI fungicide is a continuous variable indicating the continuum of sensitivity to the fungicide because individual isolates will grow at a rate dependent on their intrinsic sensitivity (Fig. 1). RG values and the resistance threshold used here are comparable with the methods used by Köller et al. (20). To allow for comparison with previously published $\mathrm{EC}_{50}$ values $(21,38)$, isolates tested on fenbuconazole and difenoconazole were also evaluated at the 0.25 and $0.125 \mu \mathrm{g} / \mathrm{ml}$ concentrations, respectively. Isolates with RG values $\geq 75$ at these concentrations were classified as "shifted" toward resistance to these products to obtain a binary variable similar to that described for resistance.

The RG of an isolate $i$ from an orchard subjected to a set of $m$ management practices (i.e., factors) can be modeled as follows:

$$
y_{i}=\mu+\alpha_{1} x_{1 i}+\alpha_{2} x_{2 i}+\ldots \alpha_{m} x_{m i}+e_{i}
$$

where $y_{i}$ is the response ( $\mathrm{RG}$ ) of isolate $i$ and, $\mu$ is the overall population mean, $\alpha$ s are fixed but unknown parameters quantifying the effects of management factors $\left(x_{1}, x_{2}, \ldots, x_{m}\right)$ on the isolate. The $e_{i}$ represents the random variation on the mean response of each isolate to the management effects and is assumed to follow an independent normal distribution with mean 0 and a variance $\sigma^{2}$ (i.e., $e_{i} \sim N\left[0, \sigma^{2}\right]$ ); therefore, the variance of the individual isolate is $\operatorname{var}\left(y_{i}\right)=\sigma^{2}$. For $n$ isolates subject to $m$ management factors, there are $n$ responses $y_{1}, y_{2}, \ldots, y_{n}$, each with its own relationship with explanatory variables identical to equation 1, except for the subscripts to identify individual isolates. The $x$ s can take the form of continuous variables or, as in our case, categorical variables representing orchard management practices. The model representing the responses of $n$ isolates can be rewritten in matrix notation as follows:

$$
\mathbf{y}=\mathbf{X} \alpha+\mathbf{e}
$$

The bold notation indicates that $\mathbf{y}$ is a vector of observed responses, $\mathbf{X}$ is a design matrix of $x \mathrm{~s}, \boldsymbol{\alpha}$ is a vector of unknown parameters to be estimated, and $\mathbf{e}$ is the vector of independent and normally distributed random errors. 
Two other assumptions were made about the populations of $V$. inaequalis evaluated in this study; namely, that (i) the 20 orchards surveyed represent a random sample of all orchards within Pennsylvania and (ii) the isolates obtained during the survey represent a random sample of the entire $V$. inaequalis population within an orchard. As a consequence, it is expected that variation occurs in RG values among isolates from different orchards and that the responses of isolates from the same orchard are correlated. The effects of this between-orchard variation on the RG of a given isolate $(i)$ can be modeled with a mixed-model approach $(4,22)$ by expanding equation 1 :

$$
\begin{gathered}
y_{i j}=\mu+\alpha_{1} x_{1 i j}+\alpha_{2} x_{2 i j}+\ldots \alpha_{m} x_{m i j}+b_{j}+e_{i} \\
e_{i} \sim N\left(0, \sigma^{2}\right) \\
b_{j} \sim N\left(0, \sigma_{b}^{2}\right)
\end{gathered}
$$

where $b_{j}$ represents the random effects of the $j$ th orchard, while $\mu$, $\alpha x_{i}$, and $e_{i}$ are as defined in equation 1. The orchards are assumed to be drawn from a random sample with a normal distribution with a mean $=0$ and a variance $\sigma_{b}^{2}$. For $n$ isolates, $m$ management factors, and $p$ random effects, a more general form of equation 3 that allows for the joint modeling of the effects of various orchard management factors can be specified as:

$$
\mathbf{y}=\mathbf{X} \alpha+\mathbf{Z} \beta+\mathbf{e}
$$

where $\mathbf{y}, \mathbf{X} \alpha$, and $\mathbf{e}$ are as defined in equation $2, \boldsymbol{\beta}$ is a vector of parameters represent the random effects, and $\mathbf{Z}$ is a design matrix for the random variables. That is, $\alpha=\left(\mu, \alpha_{1}, \alpha_{2}, \ldots, \alpha_{m}\right), \beta=\left(\beta_{1}\right.$, $\left.\beta_{2}, \ldots, \beta_{p}\right)$, and $\mathbf{e}=\left(e_{1}, e_{2}, \ldots, e_{n}\right)$. Each of the random effects in model contributes to the overall variation in the response of the $i$ th isolate through a variance component parameter that quantifies the random variation due to that effect only. Thus, the variance in the response of an individual isolate based on the random-effects model with orchards as the only random effects was $\operatorname{var}\left(y_{i}\right)=\sigma^{2}+$ $\sigma_{b}^{2}$.

The model in equation 4 was used to analyze data on RG values from 20 orchards (a continuous variable with a normal distribution) and to obtain the solutions for parameters describing the fixed effects representing the orchard management factors. Only "orchard" was specified as a random effect in the model because, in preliminary analysis, including a random-effects parameter defining isolates nested within an orchard did not result in significantly better models. Orchard management factors were analyzed as fixed effects and separate models were fit for data on each fungicide. Models were fitted with the restricted maximum likelihood method using the GLIMMIX procedure of SAS (version 9.2; SAS Institute Inc.). The best model was selected based on several criteria, including the Akaike information criterion (1) and the negative log likelihood, or deviance (26). For a given set of fitted models, the model resulting in the minimum value of these statistics corresponds to the best-fitting model. The models were also evaluated for goodness of fit by examining plots of Studentized residuals. The effects of various orchard management practices were evaluated based on the type III analysis of fixed effects, with the denominator degrees of freedom adjusted for bias with a Kenward and Roger's method (15). The lsmeans statement of GLIMMIX was used to obtain estimates and standard errors and contrasts for the fixed effects along with their $95 \%$ confidence intervals $(95 \% \mathrm{CI})$.

The mixed models used to analyze RG data were generalized to accommodate the binary variable describing the resistance status based on a specified threshold $(0.5 \mu \mathrm{g} / \mathrm{ml}$ for resistance or 0.125 and $0.25 \mu \mathrm{g} / \mathrm{ml}$ for shifted sensitivity to difenoconazole and febuconazole, respectively). This was done by specifying the binary distribution and a logit link function in the model statement of the GLIMMIX procedure. The resulting model was

$$
\operatorname{logit}\left(p_{i j}\right)=\mu+\alpha_{1} x_{1 i j}+\alpha_{2} x_{2 i j}+\ldots \alpha_{m} x_{m i j}+b_{j}
$$

with $b_{j} \sim N\left(0, \sigma_{b}^{2}\right)$, where $p_{i j}$ is the probability that the response of isolate $i$ has a value of 1 (i.e., $y_{i}=1$ ), and the other terms are as defined in equation 3 . The parameterization in matrix notation is similar to that for model in equation 4 . Note that, for reasons beyond the scope of this article, no error term is specified in this model. Mathematical and statistical details relating to the generalized linear mixed models can be found in McCullough and Neider (26), Littell et al. (22), and Brown and Prescot (4). The effects of any of the terms in the model can be interpreted in terms of odds ratios $r$, computed by taking exponential of the parameter estimates (e.g., the odds ratio of the first explanatory variable is given by $\left.r_{1}=\exp \left(\alpha_{1}\right)\right)$. Models were then fitted with the residual pseudo-likelihood method, and the effects of orchard management factors evaluated based on the $F$ statistic from the type III tests of fixed effects, with degrees of freedom adjusted for bias with the Kenward and Roger's method. Model selection and evaluation for goodness of fit was as described above for the mixed models for variables with normal distribution. The lsmeans statement of GLIMMIX was used to compute point estimates of odds ratio contrasts of fixed effects and their 95\% CI. For comparison, the same models but without specifying the random effects (i.e., a fixed-effects model identical to the random-effects model) were evaluated on the binary data.

Frequency distribution histograms of the RG values of isolates, evaluated at $0.5 \mu \mathrm{g} / \mathrm{ml}$, were plotted in SigmaPlot software (SigmaPlot for Windows Version 10; Systat Software Inc.). To test the hypothesis that isolates were cross resistant to the three fungicides, RG rates of the isolates with each fungicide at $0.5 \mu \mathrm{g} / \mathrm{ml}$ were subjected to Spearman's rank correlation analysis. The hypothetical relationship depicting the resistance status among the 498 individual isolates screened on all three fungicides was illustrated with a Venn diagram (35).

\section{RESULTS}

Estimates of $\mathrm{EC}_{50}$ values for myclobutanil, fenbuconazole, and difenoconazole. Of the 20 orchards surveyed over the 2 years, mean $\mathrm{EC}_{50}$ values were computed for 14 orchards. Overall, $\mathrm{EC}_{50}$ values were higher for myclobutanil than for fenbuconazole or difenoconazole. Orchard mean $\mathrm{EC}_{50}$ values were 1.120 to $3.534 \mu \mathrm{g} / \mathrm{ml}$ with a mean of $2.136 \pm 0.116 \mu \mathrm{g} / \mathrm{ml}$ (mean \pm standard error) for myclobutanil, 0.240 to $1.123 \mu \mathrm{g} / \mathrm{ml}$ and a mean of $0.786 \pm 0.048 \mu \mathrm{g} / \mathrm{ml}$ for fenbuconazole, and 0.041 to $0.277 \mu \mathrm{g} / \mathrm{ml}$ and a mean of $0.187 \pm 0.009 \mu \mathrm{g} / \mathrm{ml}$ for difenoconazole (Table 1). Interestingly, the highest mean $\mathrm{EC}_{50}$ values were observed for isolates obtained from cultivars grown for the processing market, although these cultivars were different for each fungicide. Among the orchards, isolates from the Golden Delicious from orchard $\mathrm{BC}-1$ had the highest mean $\mathrm{EC}_{50}$ on myclobutanil $(3.534 \mu \mathrm{g} / \mathrm{ml})$ (Table 1$)$. Isolates from Rome Beauty in $\mathrm{AC}-10$ had the highest mean $\mathrm{EC}_{50}$ value on fenbuconazole, $1.188 \mu \mathrm{g} / \mathrm{ml}$, and isolates from York Imperial in the AC-5 population had the highest difenoconazole mean $\mathrm{EC}_{50}$ value at 0.277 $\mu \mathrm{g} / \mathrm{ml}$ (Table 1). There were highly significant correlations among $\mathrm{EC}_{50}$ values for the different fungicides based on Spearman's rank correlation tests. The correlation coefficient between $\mathrm{EC}_{50}$ values for myclobutanil and fenbuconazole was $0.670(t=6.049 ; P<$ $0.001)$ and 0.605 for myclobutanil and difenoconazole $(t=5.102$; $P<0.001)$. The correlation between $\mathrm{EC}_{50}$ values for fenbuconazole and difenoconazole was $0.650(t=5.743 ; P<0.001)$.

Resistance to myclobutanil, fenbuconazole, and difenoconazole. A frequency distribution histogram demonstrated that the distribution of $\mathrm{RG}$ values on myclobutanil at $0.5 \mu \mathrm{g} / \mathrm{ml}$ was approximately normal, with a mean of 80.3 and a median of 83.1 (Fig. 1A). In comparison, the mean RG value for replicates of the two baseline isolates with myclobutanil at $0.5 \mu \mathrm{g} / \mathrm{ml}$ was 21.7 $(n=33)$ (Fig. 1A). In all, $\approx 66 \%$ of the 644 isolates tested on myclobutanil had RG values $\geq 75$, the threshold RG for desig- 
nating an isolate as resistant (Fig. 1A). For fenbuconazole, $\approx 26 \%$ of the 545 isolates tested were resistant, and the distribution of $\mathrm{RG}$ values on this product at $0.5 \mu \mathrm{g} / \mathrm{ml}$ also approximated a normal distribution (Fig. 1B). The mean and median RG of the population tested on fenbuconazole at $0.5 \mu \mathrm{g} / \mathrm{ml}$ were 57.1 and 61.5 , respectively, compared with the baseline replicates' mean RG value of $6.8(n=27)$. The distribution of the RG values on difenoconazole at $0.5 \mu \mathrm{g} / \mathrm{ml}$ was skewed to the right, typical of a lognormal distribution (28), with a mean RG of 14.5 and median RG of $12.3(n=539)$ (Fig. 1C). Only 2 of the 539 isolates (i.e., $0.37 \%$ ) analyzed were resistant to difenoconazole at $0.5 \mu \mathrm{g} / \mathrm{ml}$, with the majority of isolates having an $\mathrm{RG} \leq 25$ (Fig. 1C).

When evaluated at the lower concentrations, $47 \%$ of isolates were shifted toward resistance on fenbuconazole at $0.25 \mu \mathrm{g} / \mathrm{ml}$, while $9 \%$ were shifted toward resistance on difenoconazole at $0.125 \mu \mathrm{g} / \mathrm{ml}$ (Fig. 2). The mean and median RG values on fenbuconazole at $0.25 \mu \mathrm{g} / \mathrm{ml}$ were 68.4 and 72.5 , respectively (Fig. $2 \mathrm{~A})$. The mean and median $\mathrm{RG}$ values on difenoconazole at
$0.125 \mu \mathrm{g} / \mathrm{ml}$ were 39.5 and 36.7 , respectively (Fig. 2B). In comparison, average RG values of the confirmed baseline isolates on fenbuconazole at $0.25 \mu \mathrm{g} / \mathrm{ml}$ and difenoconazole at $0.125 \mu \mathrm{g} / \mathrm{ml}$ were 14.8 and 3.5 , respectively.

Incidence of cross resistance to DMI fungicides among isolates. In total, 498 isolates were tested on each of the three DMI fungicides. Of these, $\approx 22 \%$ of isolates were resistant to both myclobutanil and fenbuconazole, whereas only two isolates $(0.40 \%)$ were resistant to all three active ingredients based on a $0.5 \mu \mathrm{g} / \mathrm{ml}$ threshold for each fungicide (Fig. 3). Isolates with cross resistance to myclobutanil and fenbuconazole had incidences $>50 \%$ in five of the populations (AC-3, AC-4, AC-7, AC-8, and $\mathrm{BC}-1)$ (data not shown) but the incidence of cross resistant isolates varied among orchards. For example, whereas none of the isolates from orchard FC-1 were cross resistant to myclobutanil and fenbuconazole, $65 \%$ of isolates from orchard AC-8 were cross resistant to these fungicides (data not shown). As noted for $\mathrm{EC}_{50}$ values, orchard mean $\mathrm{RG}$ values for isolates tested sepa-

TABLE 1. Mean effective concentration for $50 \%$ inhibition $\left(\mathrm{EC}_{50}\right)$ values and corresponding limits of the $95 \%$ confidence interval $(95 \% \mathrm{CI}, \mu \mathrm{g} / \mathrm{ml})$ for Venturia inaequalis isolates from 14 Pennsylvania apple orchards tested on the sterol demethylation-inhibitor fungicides myclobutanil, fenbuconazole, and difenoconazole, based on samples collected in $2009^{\mathrm{a}}$

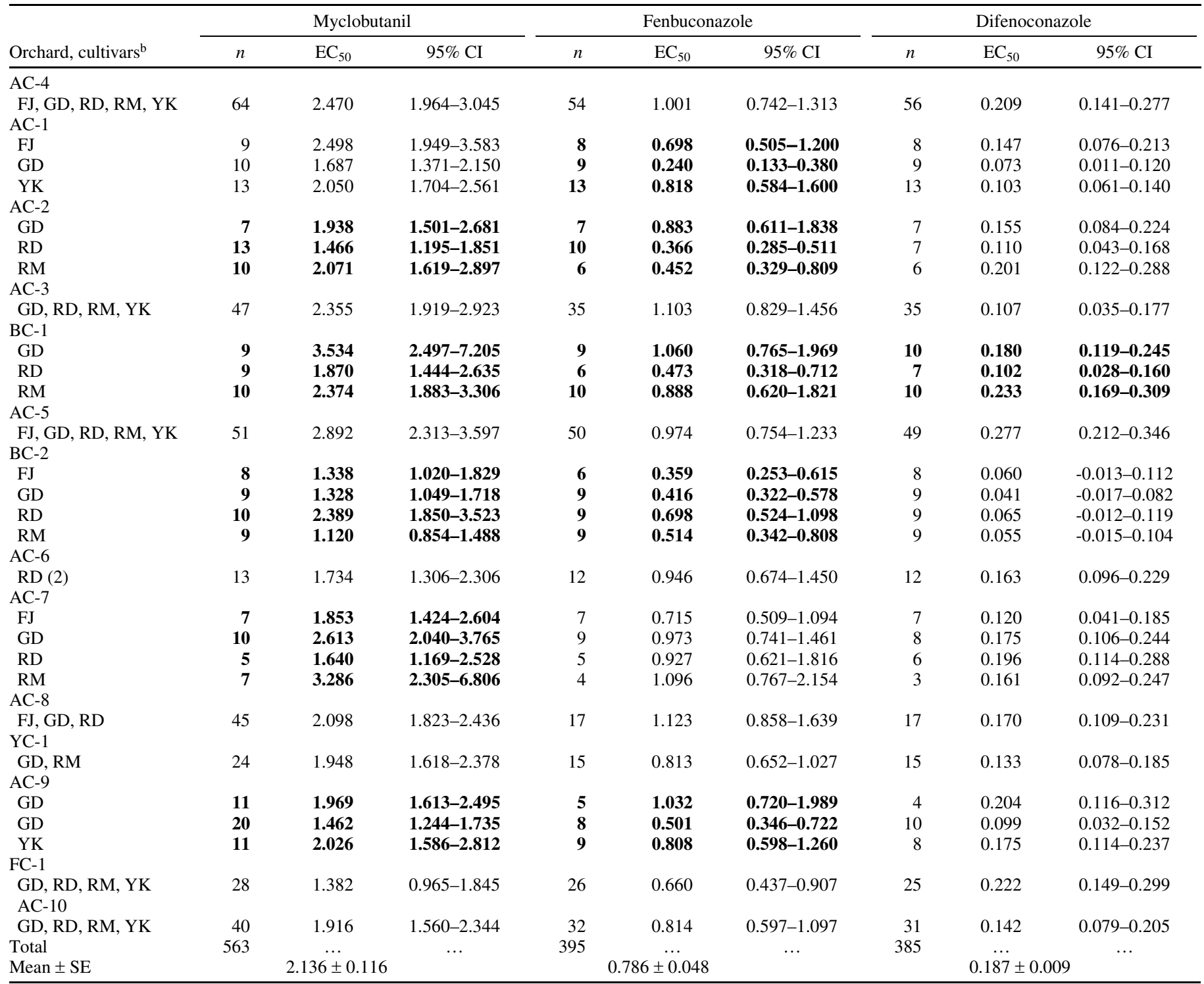

${ }^{a}$ Mean $\mathrm{EC}_{50}$ values were calculated with the probit analysis based on relative growth rates of three replicate plates of each isolate on quarter-strength potato dextrose agar medium amended with a range of concentrations of each fungicide. Values in bold indicate orchards and fungicides for which cultivars have different mean $\mathrm{EC}_{50}$ values $(P<0.05) ; n=$ number of isolates from each orchard that were screened.

${ }^{\mathrm{b}}$ Cultivars from which diseased tissue for $V$. inaequalis isolation was collected: FJ $=$ Fuji, GD = Golden Delicious, RD $=($ Red $)$ Delicious, RM $=$ Rome Beauty, and $\mathrm{YK}=$ York Imperial. $\mathrm{SE}=$ standard error. 
rately on each of the three active ingredients at $0.5 \mu \mathrm{g} / \mathrm{ml}$ were also highly correlated. The Spearman's rank correlation coefficient was $r=0.631(t=3.82 ; P=0.001)$ for the association between mean RG values of isolates on myclobutanil and fenbuconazole, and $0.672(t=5.81 ; P<0.001)$ for the correlation between the mean RG values for fenbuconazole and difenoconazole.

Evidence for between-year population shift toward increased resistance. Orchards sampled in both 2008 and 2009 were compared based on the mean $\mathrm{EC}_{50}$ values and the median $\mathrm{RG}$ values of their $V$. inaequalis populations of myclobutanil at $0.5 \mu \mathrm{g} / \mathrm{ml}$ (Table 2). A significant difference $(P=0.005)$ in the estimates of mean $\mathrm{EC}_{50}$ values for isolates from the two sample years was noted only for values from one of the three orchards (AC-4) but only after subjecting the $\mathrm{EC}_{50}$ data to a natural $\log$ transformation before the $t$ test. However, when the $\mathrm{EC}_{50}$ values were analyzed with the nonparametric K-S test, significantly higher values in 2009 were noted for populations from orchard AC-1 $(P=0.047)$ and AC-4 $(P=0.007)$ (data not shown). This outcome was confirmed with analysis based on RG values, whereby the mean and median $\mathrm{RG}$ values increased significantly $(P=0.029$ for AC- 1 and $P=0.005$ for AC-4 based on the K-S test) (Table 2) in the two orchards, even though the use of DMI fungicides was discontinued in AC-1. For example, the median RG value for isolates from orchard AC-1 increased from 73.58 in 2008 to 89.22 in 2009 while the mean RG for populations AC-4 increased from 60.39 to 83.28 over the same period (Table 2).

Orchard management practices associated with $\mathbf{V}$. inaequalis resistance to DMI fungicides. Not using copper on dormant trees or debris, larger orchards, and >4 DMI applications in 2009
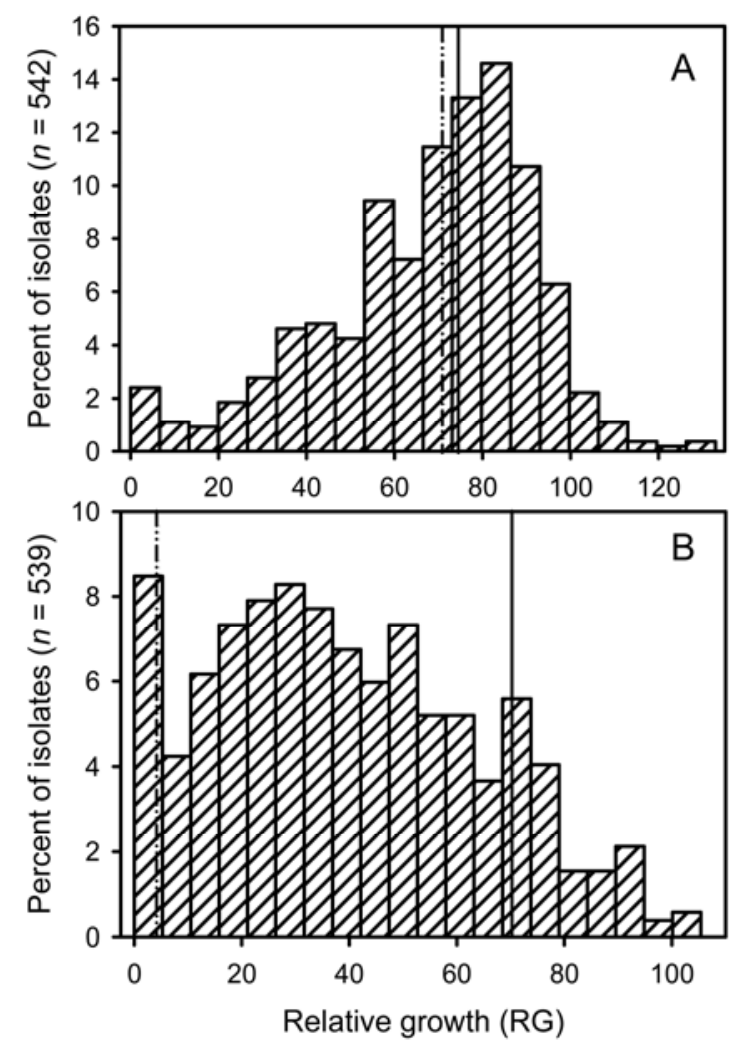

Fig. 2. Distributions of relative growth (RG) values of Venturia inaequalis isolates from Pennsylvania apple orchards on A, fenbuconazole at $0.25 \mu \mathrm{g} / \mathrm{ml}$ and $\mathbf{B}$, difenoconazole at $0.125 \mu \mathrm{g} / \mathrm{ml}$ based on samples collected in 2008 and 2009. Bars represent percent isolates in each RG category based on a sample of 542 isolates for fenbuconazole and 539 isolates for difenoconazole. Dotdash vertical lines indicate the average RG value of two isolates with confirmed shifted sensitivity (A, $n=27$ and $\mathrm{B}, n=25$ ). Solid vertical lines indicate a threshold value $(R G=75)$; isolates with $R G$ value above this threshold determined to be shifted toward resistance to the fungicide. were correlated with a high incidence of $V$. inaequalis isolates classified as resistant to myclobutanil at $0.5 \mu \mathrm{g} / \mathrm{ml}$ (Table 3). This association was significant regardless of whether data were analyzed with a random- or fixed-effects model; however, wider CIs were obtained for estimates of the random-effects model (Table 3 ). Isolates from orchards not using copper were almost twice as likely to be resistant to myclobutanil (odds ratio $=1.90 ; 95 \% \mathrm{CI}=$ 1.03 to 3.48 ) while those from orchards with $>4$ DMI applications were more than three times as likely to be resistant (odds ratio = $3.27 ; 95 \% \mathrm{CI}=1.26$ to 8.47 ) (Table 3 ). In a random-effects model analysis of continuous RG data, only use of dormant copper and number of DMI applications but not orchard size were significantly related to RG values. Isolates from orchards using dormant copper had a mean RG value of 75.3 , which was significantly $(P=0.019)$ smaller than 84.7 for isolates from orchards that did not use that practice (Fig. 4A). Mean RG values were 73.5 and 86.4 for orchards with $\leq 4$ and $>4$ DMI applications, respectively $(P=0.046)$ (Fig. 4A).

Orchard size, the use of dormant copper, age of trees, number of cultivars grown in an orchard, and the number of DMI fungicide sprays in 2009 were the factors significantly associated with the incidence of isolates shifted toward resistance to fenbuconazole evaluated at $0.25 \mu \mathrm{g} / \mathrm{ml}$ (Table 3). As with data on myclobutanil, there were only minor differences between the random- and fixed-effects models in the estimates of the odds ratios but estimates from the random-effects model had much wider CIs (Table 3). The results of this categorical data analysis were confirmed when RG values of the isolates evaluated on fenbuconazole at $0.5 \mu \mathrm{g} / \mathrm{ml}$ were analyzed in a random-effects model. Except for age of trees within an orchard, use of copper sprays on dormant trees, limiting the number of DMI applications to $\leq 4$, planting $\leq 10$ cultivars, and younger trees were significantly related to reduced $V$. inaequalis $\mathrm{RG}$ rates on media amended with fenbuconazole at $0.5 \mu \mathrm{g} / \mathrm{ml}(0.008 \leq P \leq 0.039)$ (Fig. 4B and C).

There were too few isolates deemed resistant to difenoconazole to permit an assessment of the effects of orchard management factors with the categorical data analysis techniques. However, a random-effects model showed that isolates from larger orchards $(P=0.0005)$, and those with $>4$ DMI applications in $2009(P=$ $0.0179)$, had significantly larger RG values than isolates from smaller orchards and those with fewer DMI applications, respectively. For example, the mean RG value for isolates from orchards $>25$ acres grown on 1/4 PDA plates amended with difenoconazole

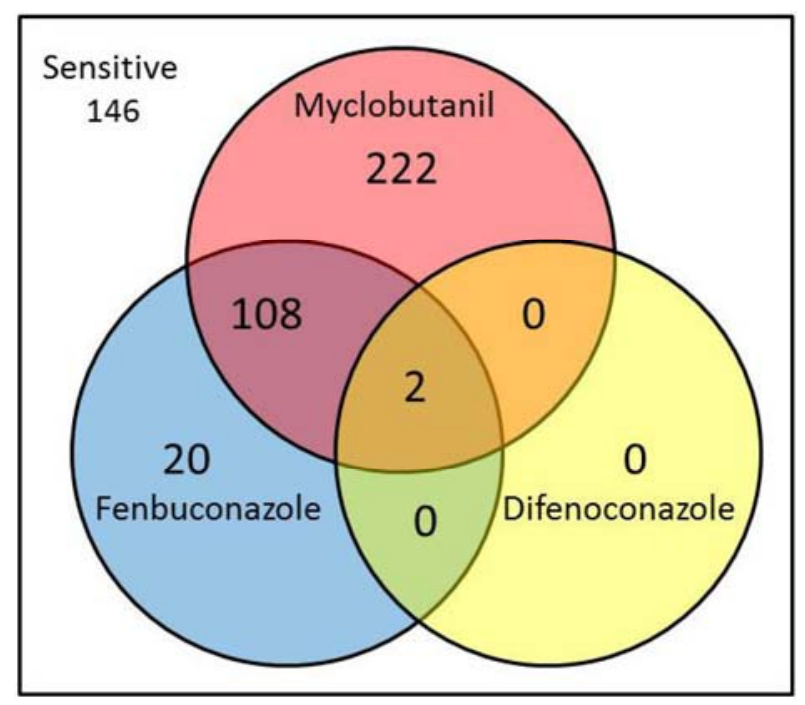

Fig. 3. Incidence of cross resistance among Venturia inaequalis isolates from Pennsylvania apple orchards tested on myclobutanil, fenbuconazole, and difenoconazole at $0.5 \mu \mathrm{g} / \mathrm{ml}$ based on samples collected in 2008 and 2009 . Values are number of isolates in each category $(n=498)$. 
at $0.125 \mu \mathrm{g} / \mathrm{ml}$ was 47.9 compared with 27.4 for isolates from orchards that were $\leq 25$ acres in size (data not shown).

Management practices associated with cross-shifted isolates. Cross-shifted isolates had $R G$ values $\geq 75$ when screened on myclobutanil at $0.5 \mu \mathrm{g} / \mathrm{ml}$, fenbuconazole at $0.25 \mu \mathrm{g} / \mathrm{ml}$, and difenoconazole at $0.125 \mu \mathrm{g} / \mathrm{ml}$. Dormant copper applications, younger trees, and smaller orchards were all associated with a reduced incidence of cross-shifted isolates (Table 4). For example, the incidence of cross-shifted isolates in orchards with $\leq 25$ acres was $17.7 \%$ compared with $33.3 \%$ for orchards $>25$ acres in size $\left(\chi^{2}=10.67, P=0.001\right)$ (Fig. 4$)$, whereas the odds of an isolate from an orchard not using dormant copper being cross-shifted were almost twice that for an isolate from an orchard practicing dormant copper application (odds ratio $=1.76 ; 95 \% \mathrm{CI}=1.01$ to 3.09; $P=0.048$ ) (Table 4). Moreover, a random-effects model confirmed that the cross-shifted isolates had significantly higher mean RG rates on all three fungicides and were also associated with higher orchard mean $\mathrm{EC}_{50}$ values (data not shown).

\section{DISCUSSION}

Estimates of the mean concentration of an active ingredient that is effective at inhibiting $50 \%$ of the growth of the sampled population ( $\mathrm{EC}_{50}$ values) provide a universally comparable statistic for differentiating levels of sensitivity to toxins among diverse populations. In the literature, $\mathrm{EC}_{50}$ values for $V$. inaequalis populations from orchards with a history of DMI fungicide use range from $0.09 \mu \mathrm{g} / \mathrm{ml}$ for fenbuconazole to $5.213 \mu \mathrm{g} / \mathrm{ml}$ for myclobutanil $(11,21)$. At the time of sample collection in this study, mean $\mathrm{EC}_{50}$ values for $V$. inaequalis populations in Pennsylvania apple orchards were within or above these estimates, at 1.120 to 3.534 $\mu \mathrm{g} / \mathrm{ml}$ for myclobutanil, 0.240 to $1.123 \mu \mathrm{g} / \mathrm{ml}$ for fenbuconazole, and 0.041 to $0.277 \mu \mathrm{g} / \mathrm{ml}$ for difenoconazole, which confirms widespread resistance or shifts toward resistance to these fungicides (Table 1). One study from the United Kingdom suggests that satisfactory scab control may only become a problem at orchard $\mathrm{EC}_{50}$ values $>2.0 \mu \mathrm{g} / \mathrm{ml}$ for myclobutanil (11). Of the 14 95\% CIs of the $\mathrm{EC}_{50}$ values from Pennsylvania orchards sampled in this study, 12 exceed that level (Table 1) and confirm grower observations of scab control failure for myclobutanil, which prompted this study.

RG values determined at discriminatory doses are also a straightforward way to determine sensitivity to fungicides (20), and this study used a concentration of myclobutanil at $0.5 \mu \mathrm{g} / \mathrm{ml}$ as the threshold for resistance. This threshold, which is more conservative than that of Köller et al. (20), was selected to allow comparison of our results with more recent studies $(10,25)$, and because lower concentrations of myclobutanil did not inhibit

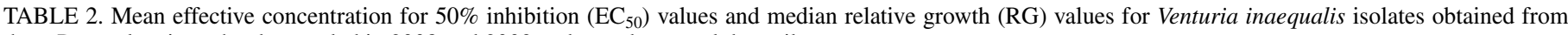
three Pennsylvania orchards sampled in 2008 and 2009 and tested on myclobutanil

\begin{tabular}{|c|c|c|c|c|c|c|c|c|c|c|c|c|c|c|}
\hline \multirow[b]{3}{*}{ Orchard } & \multicolumn{6}{|c|}{2008} & \multicolumn{6}{|c|}{2009} & & \\
\hline & \multirow[b]{2}{*}{$n^{\mathrm{a}}$} & \multirow[b]{2}{*}{$\mathrm{DMI}^{\mathrm{b}}$} & \multicolumn{2}{|c|}{$\mathrm{EC}_{50}(\mu \mathrm{g} / \mathrm{ml})^{\mathrm{c}}$} & \multicolumn{2}{|c|}{$\mathrm{RG}^{\mathrm{d}}$} & \multirow[b]{2}{*}{$n$} & \multirow[b]{2}{*}{ DMI } & \multicolumn{2}{|c|}{$\mathrm{EC}_{50}(\mu \mathrm{g} / \mathrm{ml})$} & \multicolumn{2}{|c|}{$\mathrm{RG}$} & \multicolumn{2}{|c|}{ Probability } \\
\hline & & & Mean ${ }^{f}$ & $95 \% \mathrm{CI}^{\mathrm{g}}$ & Median & Mean & & & Mean & $95 \% \mathrm{CI}$ & Median & Mean & $t$ test $^{\mathrm{h}}$ & $\mathrm{K}-\mathrm{S}^{\mathrm{i}}$ \\
\hline$\overline{\mathrm{AC}-1}$ & 19 & Yes & 2.39 & $1.93-3.99$ & 73.58 & 74.89 & 20 & No & 2.34 & $1.99-2.70$ & 89.22 & 85.45 & 0.220 & 0.029 \\
\hline AC-4 & 35 & Yes & 2.09 & $1.63-3.20$ & 71.03 & 60.39 & 19 & Yes & 2.44 & $2.33-3.97$ & 77.08 & 83.28 & 0.005 & 0.005 \\
\hline AC- 8 & 20 & Yes & 3.70 & $2.55-4.85$ & 90.08 & 80.13 & 31 & Yes & 3.68 & $2.46-4.90$ & 88.64 & 88.66 & 0.979 & 0.195 \\
\hline
\end{tabular}

a Number of isolates from cultivars sampled both years.

${ }^{b}$ Use of sterol demethylation-inhibitor (DMI) fungicides in orchard during the year the samples were collected.

${ }^{c} \mathrm{EC}_{50}$ estimates.

${ }^{\mathrm{d}} \mathrm{RG}$ with myclobutanil at $0.5 \mu \mathrm{g} / \mathrm{ml}$.

e Probability for equality of estimates.

f Mean $\mathrm{EC}_{50}$.

g $\mathrm{CI}=$ confidence interval $(\mu \mathrm{g} / \mathrm{ml})$.

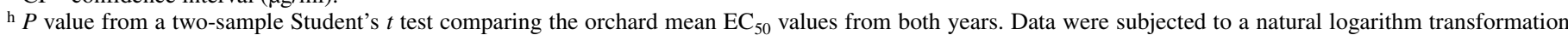
before the $t$ test.

i $P$ value from a nonparametric Kolmogorov-Smirnov (K-S) test comparing the distribution of RG values from both years.

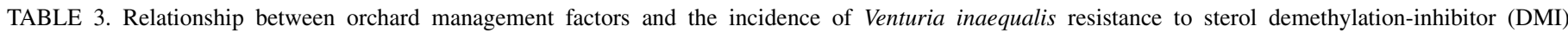
fungicides in Pennsylvania apple orchards based on samples collected in 2008 and 2009

\begin{tabular}{|c|c|c|c|c|c|c|c|c|}
\hline \multirow[b]{2}{*}{ Response variable, factor compared ${ }^{\mathrm{a}}$} & \multicolumn{4}{|c|}{ Random-effects model ${ }^{\mathrm{b}}$} & \multicolumn{4}{|c|}{ Fixed-effects model ${ }^{\mathrm{c}}$} \\
\hline & Odds ratio & $95 \% \mathrm{CI}^{\mathrm{d}}$ & $F$ value & $P$ value & Odds ratio & $95 \% \mathrm{CI}$ & $F$ value & $P$ value \\
\hline \multicolumn{9}{|l|}{ Resistant to myclobutanil ${ }^{\mathrm{e}}$} \\
\hline Copper vs. no copper & 1.90 & $1.03-3.48$ & 4.30 & 0.0386 & 2.10 & $1.50-2.95$ & 18.34 & $<0.0001$ \\
\hline Small vs. large orchards & 0.38 & $0.15-0.98$ & 4.03 & 0.0450 & 0.36 & $0.21-0.59$ & 15.78 & $<0.0001$ \\
\hline$\leq 4$ vs. $>4$ DMI applications in 2009 & 3.27 & $1.26-8.47$ & 5.96 & 0.0149 & 3.06 & $1.50-2.95$ & 19.34 & $<0.0001$ \\
\hline \multicolumn{9}{|l|}{ Shifted sensitivity to fenbuconazole ${ }^{f}$} \\
\hline Copper vs. no copper & 2.02 & $1.05-3.91$ & 5.75 & 0.0382 & 1.92 & $1.25-2.95$ & 10.81 & 0.0029 \\
\hline Small vs. large orchards & 0.16 & $0.06-0.46$ & 16.24 & 0.0041 & 0.15 & $0.08-0.29$ & 32.97 & $<0.0001$ \\
\hline$\leq 4$ vs. $>4$ DMI applications in 2009 & 4.57 & $1.48-9.16$ & 9.84 & 0.0150 & 4.44 & $2.31-8.55$ & 24.06 & $<0.0001$ \\
\hline Old vs. young trees & 1.72 & $1.09-2.72$ & 5.60 & 0.0200 & 1.83 & $1.24-2.71$ & 11.71 & 0.0040 \\
\hline$\geq 10$ vs. $>10$ cultivars & 0.41 & $0.18-0.91$ & 5.90 & 0.0324 & 0.43 & $0.24-0.76$ & 10.34 & 0.0025 \\
\hline
\end{tabular}

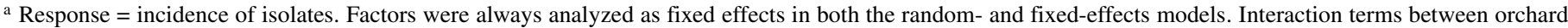
and these factors could not be estimated because each orchard had only one of two levels for each of these factors. Orchards were grouped based on (i) whether they received least one application of a copper-containing product on dormant trees or leaf litter in the fall or spring preceding the survey, (ii) size ( $\leq 25$ acres or $>25$ acres), (iii) age of trees ( $\leq 20$ years; or $>20$ years), and (iv) number of cultivars planted.

b Orchards were analyzed as a random variable in a model fitted to the binary incidence data with the GLIMMIX procedure in SAS.

c Orchard was analyzed as fixed effects in the model but not specified as a random variable in the GLIMMIX procedure.

${ }^{\mathrm{d}} \mathrm{CI}=$ confidence interval.

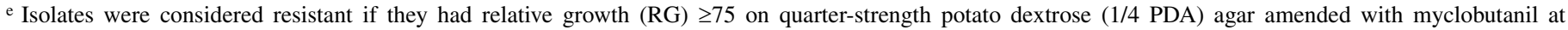
$0.5 \mu \mathrm{g} / \mathrm{ml}$.

${ }^{f}$ Isolates were considered shifted towards resistance if they had RG $\geq 75$ on $1 / 4$ PDA amended with fenbuconazole at $0.25 \mu \mathrm{g} / \mathrm{ml}$. 


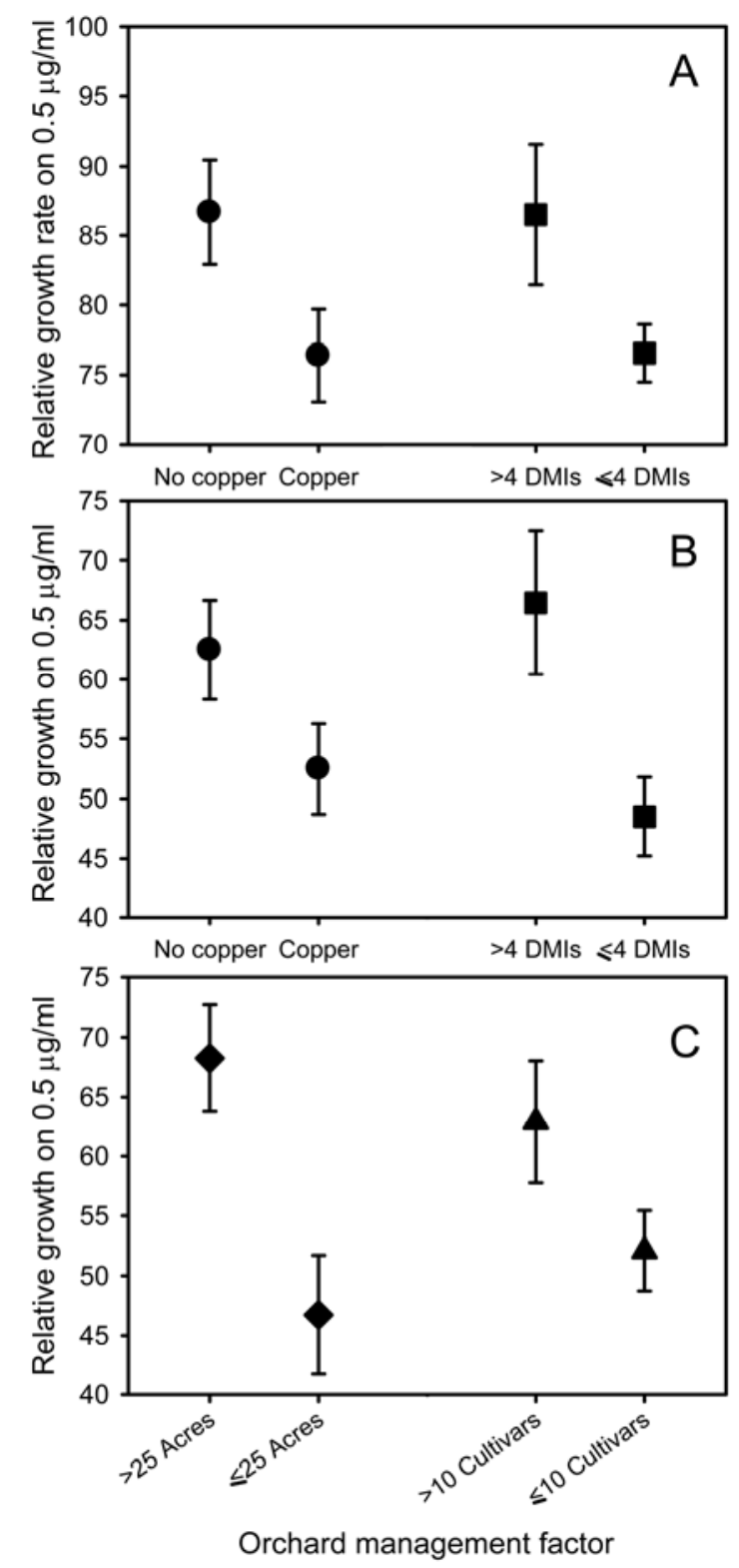

Fig. 4. Effects of dormant copper applications, number of sterol demethylation-inhibitor (DMI) sprays, orchard size, and number of cultivars planted in an orchard on growth responses of Venturia inaequalis isolates collected in 2008 and 2009 from apple orchards in Pennsylvania. Values are means and standard errors of relative growth values on plates amended with $\mathbf{A}$, myclobutanil or B and C, fenbuconazole at $0.5 \mu \mathrm{g} / \mathrm{ml}$ based on estimates obtained with a model in which orchards and isolates were analyzed as random effects. growth for the majority of the isolates in our study. Nevertheless, even with a $0.5 \mu \mathrm{g} / \mathrm{ml}$ concentration and an $\mathrm{RG}$ value of 75 as threshold, $66 \%$ of 644 isolates screened were resistant to myclobutanil, and $26 \%$ of 545 isolates were resistant to fenbuconazole (Fig. 1). When evaluated at lower concentrations of fenbuconazole and difenoconazole ( 0.25 and $0.125 \mu \mathrm{g} / \mathrm{ml}$, respectively), 47 and $9 \%$ of isolates, respectively, were shifted toward resistance to these fungicides (Fig. 2). The combined results on the estimates of $\mathrm{EC}_{50}$ values and tests based on specific discriminatory doses indicate high levels of resistance to myclobutanil and fenbuconazole, as well as strong shifts toward resistance to difenoconazole in populations of $V$. inaequalis from Pennsylvania apple orchards. Resistance to DMI fungicides has been documented in most of the apple-producing states in the eastern United States, including New York and Michigan (20) and Virginia (25), but this is the first report from Pennsylvania.

The observation that isolates were more likely to be resistant to myclobutanil than to fenbuconazole or difenoconazole (Table 1; Fig. 1) may be attributed to several factors. Myclobutanil has been used for control of apple scab in the United States for $>20$ years, whereas fenbuconazole and difenoconazole had only been used in commercial apple orchards for 3 and 1 years, respectively, at the time of this survey $(18,27)$; thus, it would be expected that populations would be most adapted to myclobutanil. The breadth of resistance to fenbuconazole is surprising, given that it has been marketed for control of apple scab for a much shorter duration than myclobutanil. This may be accounted for by the strong cross resistance to these fungicides among $V$. inaequalis populations (Fig. 3), whereby individuals exposed to myclobutanil are already preselected for resistance to fenbuconazole compared with individuals from populations with no exposure to DMI fungicides (19). Nevertheless, other factors, such as introduction of different inactive ingredients, changes in other products that are tankmixed with DMI fungicides, the overall solubility of the fungicides, and individual orchard spray schedules cannot be ignored and require further investigation.

Of the three orchards sampled in both 2008 and 2009, significant shifts toward increased resistance were noted in two of the orchards as higher median $\mathrm{RG}$ or mean $\mathrm{EC}_{50}$ values in 2009 (Table 2). Indeed, when the $\mathrm{EC}_{50}$ values were subjected to a natural $\log$ transformation before the $t$ test, or analyzed with the nonparametric K-S test, the results were congruent with those of tests based on RG values. These results, therefore, indicate reduced sensitivity to myclobutanil in the $V$. inaequalis populations from the second year of the survey for these two orchards, and provide evidence for season-to-season shifts toward increased resistance to DMI fungicides in $V$. inaequalis populations. Increased resistance in orchard $\mathrm{AC}-1$, even after DMI fungicides were withdrawn, suggests that the resistant population is ecologically fit, or had cross resistance to the fungicides used in place of the DMIs in 2009. Little is known about the rate of development of resistance to DMI fungicides in commercial apple orchards, or about the inheritance of resistance to DMI fungicides in populations of $V$. inaequalis. Knowledge of seasonal or long-

TABLE 4. Orchard management factors related to the incidence of Venturia inaequalis isolates with cross-shifted resistance to myclobutanil, fenbuconazole, and difenoconazole based on samples obtained in 2008 and 2009 from Pennsylvania apple orchards ${ }^{\text {a }}$

\begin{tabular}{lcccccc}
\hline Factor $^{\mathrm{b}}$ & ${\text { Num. } \mathrm{df}^{\mathrm{c}}}^{\mathrm{c}}$ & Den. $\mathrm{df}^{\mathrm{c}}$ & $F$ & $P>F$ & Odds ratio & $95 \% \mathrm{Cl}^{\mathrm{d}}$ \\
\hline Orchard size & 1 & 6.29 & 8.99 & 0.0227 & 0.38 & $0.174-0.830$ \\
Tree age & 1 & 30.15 & 8.13 & 0.0078 & 1.85 & $1.191-2.880$ \\
Use of copper & 1 & 5.76 & 6.25 & 0.0482 & 1.76 & $1.006-3.089$ \\
\hline
\end{tabular}

a Isolates were considered cross-shifted towards resistance if they had a relative growth value $(\mathrm{RG}) \geq 75$ on separate plates amended with myclobutanil at $0.5 \mu \mathrm{g} / \mathrm{ml}$, fenbuconazole at $0.25 \mu \mathrm{g} / \mathrm{ml}$, and difenoconazole at $0.125 \mu \mathrm{g} / \mathrm{ml}$. In total, 203 of the 630 isolates tested were cross shifted on all three fungicides.

${ }^{b}$ Based on survey response from growers whereby orchard blocks were classified based on (i) size ( $\leq 25$ acres or $>25$ acres), (ii) age of trees ( $\leq 20$ years or $>20$ years), and (iii) whether they received least one application of a copper-containing product on dormant trees or leaf litter in the fall or spring preceding the survey.

${ }^{\mathrm{c}}$ Num. $\mathrm{df}=$ numerator degrees of freedom and Den. $\mathrm{df}=$ denominator degrees of freedom adjusted for bias with the Kenward-Roger's method (15).

${ }^{\mathrm{d}} \mathrm{CI}=$ confidence interval. 
term changes in the population structure of $V$. inaequalis, therefore, would be beneficial in developing strategies for resistance management.

In total, $\approx 22 \%$ of isolates tested were cross resistant to both myclobutanil and fenbuconazole and two isolates were cross resistant to all three fungicides evaluated at the $0.5 \mu \mathrm{g} / \mathrm{ml}$ concentration (Fig. 3). Cross resistance to DMI fungicides has been documented in populations of $V$. inaequalis from the United Kingdom; however, this result was based on conidial populations, and individual isolates were not tested on each fungicide (38). Additionally, these researchers found that the incidence of cross resistance was dependent on the particular source orchard (38). In our study, isolate origin was correlated with the incidence of cross resistance to myclobutanil and fenbuconazole only $\left(\chi^{2}=45.82\right.$; $P<0.001$ ) (data not shown). By introducing a third active ingredient, difenoconazole, our data suggest at least two mechanisms conferring resistance to DMI fungicides: one determining resistance to myclobutanil and fenbuconazole and an additional mechanism, either rarely occurring or acquired with a cost to mutant individuals, that confers resistance to all three fungicides. These results, along with the widely held theory that $V$. inaequalis resistance to DMI fungicides is quantitatively inherited $(14,20)$, support the hypothesis that shifts toward resistance to active ingredients within the DMI fungicide class may be conferred by different genetic changes. We speculate that the two isolates with cross resistance to all three DMI fungicides in this study possess multiple resistance mechanisms; however, confirmation of this would require a thorough genetics characterization of these isolates.

Management factors contributing to the development of resistance to DMI fungicides were identified in this study through a survey distributed to growers. Therefore, these data are observational and care should be taken not to infer a cause-and-effect relationship from the results. Nevertheless, sufficient evidence for association between certain management factors and incidence of resistant strains was deduced even after accounting for the wide variability between orchards (resulting, for example, from correlations in responses among isolates from the same orchard) with the random-effects model (equation 5). The most notable effect of using the random-effects model was wider confidence limits

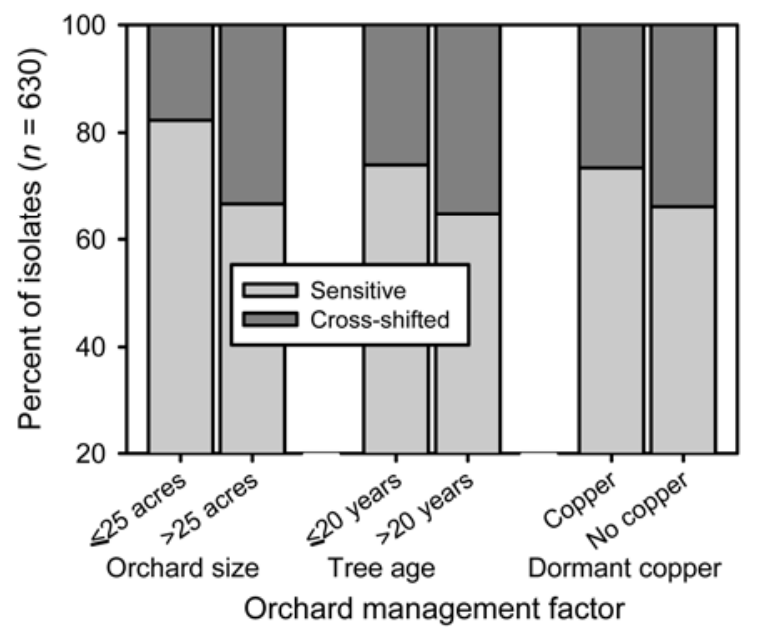

Fig. 5. Effect of orchard size, age of trees, and use of dormant copper on the incidence of Venturia inaequalis isolates obtained in 2008 or 2009 from Pennsylvania apple orchards and characterized as sensitive or cross-shifted toward resistance to myclobutanil, fenbuconazole, and difenoconazole. Isolates was considered cross-shifted toward resistance they had relative growth value $\geq 75$ on separate plates amended with myclobutanil at $0.5 \mu \mathrm{g} / \mathrm{ml}$, fenbuconazole at $0.25 \mu \mathrm{g} / \mathrm{ml}$, and difenoconazole at $0.125 \mu \mathrm{g} / \mathrm{ml}$. For each orchard management practice, the incidence of isolates in each fungicide sensitivity category was significantly different $(P<0.05)$ based on generalized linear mixed model with orchards analyzed as random effects. compared with those of the fixed-effects model (Table 3). This is not surprising because every additional random term contributes a variance component to the overall variance on which the confidence limits are based $(4,22)$. The advantage of using the randomeffects model over the fixed-effects model is that the inference about the associations can be extended to orchards other than those sampled (4).

Among all isolates tested on myclobutanil, fenbuconazole, and difenoconazole, a greater proportion of resistant isolates originated from larger orchards (more than 25 acres) than from smaller orchards (Fig. 4; Tables 3 and 4). The effect of orchard size on the resistance status of $V$. inaequalis isolates was not surprising because appropriate spray intervals or coverage can be more difficult to achieve for larger orchard operations than for smaller orchards. For example, field applicators may be covering the orchard at a faster pace because there is more area to be sprayed, or applications may be interrupted by weather events, due to the simple fact that spraying a larger orchard takes more time.

The age of trees in an orchard was a significant factor in the status of resistance to fenbuconazole (Table 3), which was also expected. Most likely, $V$. inaequalis populations in older orchards have undergone more selection pressure due to a longer duration of exposure to DMI fungicides, as has been suggested in other studies (21). This result is in contrast to an earlier study that found no difference between the $\mathrm{EC}_{50}$ values of $V$. inaequalis populations from an orchard that had been using DMI fungicides for 12 years and from an orchard that had never been treated with DMI fungicides (32). A more recent study, however, has shown a positive linear relationship between $\mathrm{RG}$ values of $V$. inaequalis isolates and the number of DMI fungicide treatments applied to the orchard (11). It is estimated that a grower may have 30 to 40 DMI applications before a shift toward resistance to the fungicides occurs in $V$. inaequalis populations $(11,18)$, and most orchards in this study had been treated with DMI fungicides for at least 10 years, with several applications per year (J. W. Travis, personal communication).

The overall diversity of the cultivars grown in an orchard had an influence on the resistance status of the $V$. inaequalis population to fenbuconazole (Table 3). Host diversity in an orchard may provide another challenge for $V$. inaequalis, in addition to that imposed by the use of DMI fungicides, thereby slowing the shift toward resistance. The number of cultivars grown in an orchard could also be an indication of the market the particular grower is focusing on; fresh-market growers may be more likely to plant a wide diversity of cultivars than growers focusing on processing-apple sales. Target markets and associated profit margins affect the approach to managing apple orchards. For example, processing-apple markets have a higher tolerance for apple scab, but processing crops also garner lower prices. This may lead to the use of less efficacious but less costly fungicides initially and, once scab incidence nears the economic threshold for processing apples, the more costly DMI fungicides may be used as a sort of "last resort" to save the crop. Such practices may account for the significantly higher mean $\mathrm{EC}_{50}$ values noted for processing cultivars (Table 1). Differential cultivar susceptibility to $V$. inaequalis has been documented $(3,5,24)$. It may be possible that strains adapted to certain cultivars are more fit overall and can withstand fungicides better than strains from other cultivars. Additional research would be required to determine if this were the case.

The positive association between the number of DMI applications per year and the incidence of resistance to fenbuconazole (Table 3; Fig. 4) is intuitive, because isolates from orchards with more DMI applications per season would be subjected to more selection events. Indeed, our data corroborate those of a recent study, in which a positive linear relationship was identified between the number of DMI applications per year and the incidence of shifts toward resistance to myclobutanil (11). Product labels for 
DMI fungicides explicitly limit the number of applications per season to four, and that recommendation has been emphasized to growers (29).

The relationship between the use of dormant copper application and resistance to DMI fungicides (Fig. 4; Tables 3 and 4) is the most noteworthy and statistically strong result in terms of DMI fungicide resistance management. Isolates from orchards that were not using copper were almost two times more likely to be cross shifted toward resistance than isolates from orchards treated with copper (Fig. 5; Table 4). A possible explanation for this relationship is that the effects of copper may be due to an overall reduction in mating populations of $V$. inaequalis that produce ascospores. An alternative explanation is that dormant copper sprays have a sanitation effect against overwintering conidial inoculum $(23,24)$. Though little is known about the heritability of resistance to DMI fungicides in $V$. inaequalis, keeping the overall season-to-season populations low and reducing the number of the more genetically diverse ascospores would slow the development of predominantly resistant populations. Higher levels of initial inoculum imply a higher likelihood of resistant propagules establishing new infections. Additionally, higher overall inoculum levels may warrant higher rates of fungicides and shorter intervals between sprays, which would increase selection pressure on the $V$. inaequalis population (18). These hypotheses require additional investigation. In the meantime, existing equipment and personnel can be used for copper application, making this an inexpensive choice for fungicide resistance management. This recommendation should be offered with caution, however, because copper toxicity in orchard soils is a concern for orchards with prolonged use of copper (36).

After testing a large collection of $V$. inaequalis isolates on myclobutanil, fenbuconazole, and difenoconazole, we conclude that myclobutanil is no longer an effective compound for control of apple scab in most Pennsylvania orchards, and that the effectiveness of fenbuconazole and difenoconazole will quickly be lost. The use of copper fungicides on trees or litter during the dormant season, the age of apple trees in an orchard, the number of cultivars grown in the orchard, the number of DMI fungicide applications, and the size of the orchard were the factors influencing the likelihood of resistance to DMI fungicides in the orchards surveyed. Our data indicate that, in addition to using products with various modes of action, the application of copper fungicides during dormant sprays and limiting the number of DMI fungicide applications per season will reduce the rate at which resistance to DMI fungicides develops in commercial apple orchards. By implementing these management strategies, growers around the world can prolong the efficacy of DMI fungicides on $V$. inaequalis populations in their orchards.

\section{ACKNOWLEDGMENTS}

This study was funded, in part, by the State Horticultural Association of Pennsylvania through grants to H. K. Ngugi. We thank K. D. Cox for providing baseline isolates from New York; J. W. Travis for very informative discussions; and T. Krawczyk, D. Scotton, and M. Norton for technical assistance.

\section{LITERATURE CITED}

1. Akaike, H. 1974. A new look at the statistical model identification. IEEE Trans. Automatic Control 19:716-723.

2. Aylor, D. E. 1998. The aerobiology of apple scab. Plant Dis. 82:838-849.

3. Barbara, D. J., Roberts, A. L., and Xu, X. M. 2008. Virulence characteristics of apple scab (Venturia inaequalis) isolates from monoculture and mixed orchards. Plant Pathol. 57:552-561.

4. Brown, H., and Prescott, R. 2006. Applied Mixed Models in Medicine, Second Edition. John Wiley \& Sons, Ltd., Chichester, UK.

5. Carisse, O., and Dewdney, M. 2002. A review of non-fungicidal approaches for the control of apple scab. Phytoprotection 83:1-29.

6. Cooley, D. R. 2009. Biorational approaches to disease management in apples. Pages 214-252 in: Biorational Tree Fruit Pest Management. T. Leskey, M. Aluja, and C. Vincent, eds. CABI Publishing, Wallingford, UK.

7. Del Sorbo, G., Andrade, A. C., Van Nistelrooy, J. G. M., Van Kan, J. A. L., Balzi, E., and De Waard, M. A. 1997. Multidrug resistance in Aspergillus nidulans involves novel ATP-binding cassette transporters. Mol. Gen. Genet. 254:417-426.

8. Delye, C., Bousset, L., and Corio-Costet, M. 1997. PCR cloning and detection of point mutations in the eburicol 14 $\alpha$-demethylase (CYP51) gene from Erysiphe graminis f. sp. hordei, a "recalcitrant" fungus. Curr. Genet. 34:399-403.

9. Delye, C., Laigret, F., and Corio-Costet, M. 1997. A mutation in the $14 \alpha$-demethylase gene of Uncinula necator that correlates with resistance to a sterol biosynthesis inhibitor. Appl. Environ. Microbiol. 63:29662970.

10. Errampalli, D. 2004. Distribution of myclobutanil fungicide sensitivities among populations of Venturia inaequalis, the causal agent of apple scab, in Ontario. Acta Horticulturae 638 IHC Sustainability of Horticultural Systems.

11. Gao, L., Berrie, A., Yang, J., and Xu, X. 2009. Within- and betweenorchard variability in the sensitivity of Venturia inaequalis to myclobutanil, a DMI fungicide, in the UK. Pest Manage. Sci. 65:1241-1249.

12. Holb, I. J. 2008. Fungal disease management in environmentally friendly apple production-a review. Sustain. Agric. Rev. 2:219-292.

13. Hsiang, T., Yang, L., and Barton, W. 1997. Baseline sensitivity and crossresistance to demethylation-inhibiting fungicides in Ontario isolates of Sclerotinia homoeocarpa. Eur. J. Plant Pathol. 5:409-416.

14. Jobin, T., and Carisse, O. 2007. Incidence of myclobutanil- and kresoximmethyl-insensitive isolates of Venturia inaequalis in Quebec orchards. Plant Dis. 91:1351-1358.

15. Kenward, M. G., and Roger, J. H. 1997. Small sample inference for fixed effects estimators from restricted maximum likelihood. Biometrics 53:983-997.

16. Kolbe, W. 1983. Effects of different pruning systems and chemical retardants compared with no pruning on apple trees on yield, fruit quality, and disease incidence in the long term trial at Hofchen (1959-1982). Erwersobstbau 25:246-255.

17. Köller, W., Parker, D. M., Turechek, W. W., and Avila-Adame, C. 2004. A two-phase resistance response of Venturia inaequalis populations to the QoI fungicides kresoxim-methyl and trifloxystrobin. Plant Dis. 88:537544.

18. Köller, W. M., Parker, D., Turechek, W., Rosenberger, D., Wilcox, W., Carroll, J., Agnello, A., and Reissig, H. 2005. Fungicide resistance of apple scab: Status quo and management options. N. Y. Fruit Q. 13:9-17.

19. Köller, W., and Wilcox, W. F. 2001. Evidence for the predisposition of fungicide-resistant isolates of Venturia inaequalis to a preferential selection for resistance to other fungicides. Phytopathology 91:776-781.

20. Köller, W., Wilcox, W .F., Barnard, J., Jones, A. L., and Braun, P. G. 1997. Detection and quantification of resistance of Venturia inaequalis populations to sterol demethylation inhibitors. Phytopathology 87:184190.

21. Kunz, S., Deising, H., and Mendgen, K. 1997. Acquisition of resistance to sterol demethylation inhibitors by populations of Venturia inaequalis. Phytopathology 87:1272-1278.

22. Littell R. C., Milken, G. A., Stroup, W. W., and Schabenberger, O. 2006. SAS for Mixed Models, Second Edition. SAS Institute Inc., Cary, NC.

23. MacHardy, W. E. 1996. Apple Scab: Biology, Epidemiology, and Management. American Phytopathological Society, St. Paul, MN

24. MacHardy, W. E., Gadoury, D. M., and Gessler, C. 2001. Parasitic and biological fitness of Venturia inaequalis: Relationship to disease management strategies. Plant Dis. 85:1036-1051.

25. Marine, S. C., Schmale, D. G., and Yoder, K. S. 2007. Resistance to myclobutanil in populations of Venturia inaequalis in Winchester, Virginia. Plant Health Progress. Online publication. doi:10.1094/PHP2007-1113-01-RS.

26. McCullough, P., and Nelder, J. A. 1989. Pages 33-35 in: Generalized Linear Models. Chapman and Hall, London.

27. National Pesticide Information Retrieval Service. 2010. http://state. ceris.purdue.edu/htbin/prtinfo.com.

28. Ngugi, H. K., King, S. B., Abayo, G. O., and Reddy, Y. V. R. 2002. Prevalence, incidence, and severity of sorghum diseases in western Kenya. Plant Dis. 86:65-70.

29. Pennsylvania Tree Fruit Production Guide. 2008-2009 Edition. The Pennsylvania State University, University Park.

30. Russell, P. E. 2005. A century of fungicide evolution. J. Agric. Sci. 143:11-25.

31. Schnabel, G., and Jones, A. L. 2001. The 14a-demethylase (CYP51A1) gene is overexpressed in Venturia inaequalis strains resistant to myclobutanil. Phytopathology 102-110.

32. Smith, F. D., Parker, D. M., and Köller, W. 1991. Sensitivity distribution 
of Venturia inaequalis to flusilazole: Baseline sensitivity and implications for resistance monitoring. Phytopathology 81:392-396.

33. Sutton, D. K., MacHardy, W. E., and Lord, W. G. 2000. Effects of shredding or treating apple leaf litter with urea on ascospore dose of Venturia inaequalis and disease buildup. Plant Dis. 84:1319-1326.

34. Travis, J. W., Ngugi, H. K., and Halbrendt, N. O. 2008. Strategic disease management. Fruit Times. 27:1-3.

35. Venn, J. 1880. On the diagrammatic and mechanical representation of propositions and reasonings. Dublin Philos. Mag. J. Sci. 10:1-18.
36. Wang, Q. Y., Zhou, D. M., and Cang, L. 2009. Microbial and enzyme properties of apple orchard soil as affected by long-term application of copper fungicide. Soil Biol. Biochem. 41:1504-1509.

37. Wyand, R. A., and Brown, J. K. M. 2005. Sequence variation in the CYP51 gene of Blumeria graminis in association with resistance to sterol demethylation inhibiting fungicides. Fungal Genet. Biol. 42:726-735.

38. Xu, X.-M., Gao, L. Q., and Yang J.-R. 2010. Are insensitivities of Venturia inaequalis to myclobutanil and fenbuconazole correlated? Crop Prot. 29:183-189. 